\title{
28 Resarch Soure \\ Chemical, biological, radiological, and nuclear preparedness of public hospitals in Riyadh
}

Ahmed Ali Alahmari ( $\square$ ahalalahmari@moh.gov.sa )

Saudi Arabia Ministry of Health https://orcid.org/0000-0003-0096-1314

Anas A Khan

King saud university

\section{Research}

Keywords: chemical, biological, radiological, and nuclear incidents, hospital preparedness, disaster, weapons of mass destruction, Saudi Arabia

Posted Date: November 13th, 2020

DOI: https://doi.org/10.21203/rs.3.rs-104590/v1

License: (1) This work is licensed under a Creative Commons Attribution 4.0 International License. Read Full License 


\section{Abstract}

Objectives

Chemical, biological, radiological, and nuclear (CBRN) incidents are those that involve chemical or biological warfare agents or toxic radiological or nuclear materials. These agents can cause disasters intentionally or accidentally. Hospitals play a crucial role in handling CBRN disasters. This study aimed to assess the CBRN preparedness of government hospitals in Riyadh.

Methods

A descriptive cross-sectional study was conducted across government hospitals in Riyadh, all government hospitals in Riyadh with more than 100 inpatient beds and an emergency department met the inclusion criteria. Hospital preparedness was assessed using an adaptation of the CBRNE Plan Checklist. Results were described in frequencies across several domains such as foundational considerations, planning, training and awareness, procedures, and modules for preparing for a biological incident, a chemical incident, and a radiological or nuclear incident.

Results

Of the 11 eligible hospitals, 10 participated in the study. Further, CBRN considerations were included in the disaster plans of 7 hospitals. Drills had been conducted in collaboration with local agencies in only 2 hospitals. The staff had been trained to recognize the signs and symptoms of exposure to class (A) biological agents in less than half of the hospitals. A majority of the hospitals had antidotes and prophylactics to manage chemical incidents, but only half of them had radiation detection instruments. Personal protective equipment was available in all hospitals, but rapid access to stockpiles of medications was available in only half of them.

Conclusion

Government hospitals in Riyadh demonstrated insufficient CBRN preparedness. Therefore, their staffs should be trained to manage CBRN emergencies, and local drills should be conducted to improve their preparedness.

\section{Introduction}

Chemical, biological, radiological, and nuclear (CBRN) emergencies involve agents like toxic and hazardous chemicals, biological warfare agents, toxic radiological or nuclear materials, and weapons of mass destruction (WMD). They can be caused either accidentally (Bhopal gas tragedy in India, Chernobyl nuclear accident in Ukraine) or intentionally (nuclear bombing of Hiroshima and Nagasaki in Japan during World War II). $(1,2,3)$ 
Moreover, CBRN events can result in mass causalities and create hazardous environments within a very short time span. $(4,5)$ Hospitals play a vital role in providing emergency care during such disasters and act as a focal point in mounting an emergency response.(6) Hospitals in the United States have been found to be inadequately prepared to handle WMD events. $(7,8)$ Similar results have also been reported for other western countries like Australia and Belgium. $(9,10)$

In the Middle East, a lack of CBRN preparedness was highlighted during the chemical attacks that Syria experienced in 2013. $(11,12)$ The need to create awareness and provide disaster training to the masses was underscored by a Saudi study that was conducted in 2012. Specifically, it found that there was a substantial lack of awareness about disasters among the general population.(13) In 2014, a study that was conducted in Mecca found that there were major deficiencies in emergency nurses' knowledge about disaster plans.(14) Further, studies that have examined the disaster preparedness of hospitals in Mecca and Riyadh have reported the following: substantially inadequate education, training, and monitoring of hospital staff, a lack of exercises and drills that promote disaster preparedness, and suboptimal hospital disaster preparedness plans. $(15,16)$

Saudi Arabia is at a risk for attacks that involve WMD. The ongoing war in neighboring countries, namely, Syria, Yemen, Israel, and Palestine, and emergence of terrorist groups in this region have increased the risk of attacks on Saudi Arabia.(17) In addition, the Government of Saudi Arabia plans to construct several nuclear power reactors over the next few years, and they carry the risk of accidental emergencies. (18) The emergence of terrorist groups such as the so-called Islamic State in Iraq and Syria, Al-Qaeda, and Hezbollah has also increased the chances of attacks on Saudi Arabia because it vehemently opposes their terrorist activities. The constant barrage of rockets and missiles that have been launched from Houthi-held Yemeni territories over Saudi Arabia, especially Riyadh city, highlight the need for disaster preparedness among Saudi institutions and society.(17)

Hospitals play an important role in mitigating the effect of any disaster. A number of research initiatives that are related to hospital preparedness for CBRN events have been implemented around the world, but such studies have not yet been widely conducted in Saudi Arabia. Hence, this study aimed to assess the CBRN preparedness of government hospitals in Riyadh.

\section{Methods}

A descriptive cross-sectional study was conducted across government hospitals in Riyadh. Specifically, government hospitals in Riyadh that had more than 100 inpatient beds and an emergency department, and had been included in the national disaster plan were eligible for inclusion. Hospitals that were specialized entities (King Khalid Eye Hospital) and had fewer than 100 inpatient beds were excluded. All units that met the aforementioned criteria were included.

The CBRNE (chemical, biological, radiological, nuclear, or explosive event) Plan Checklist, which has been developed by The Centre for Excellence in Emergence Preparedness in Canada, was adapted and used in the present study. (20) This checklist was considered to be most relevant to the objectives of the current 
study. The checklist was designed so that facilities can use it to conduct assessments and initiate dialogues with key stakeholders within their respective facilities. This tool has 7 sections: (i) foundational considerations, (ii) planning, (iii) training and awareness, (iv) procedures, and (v-vii) modules for CBRN incidents. The incident commander of each hospital responded to the checklist. If such a position did not exist in a hospital, the head of the emergency department or medical director completed the checklist.

Data were electronically entered and imported into Microsoft Excel. Descriptive statistics, namely, frequencies and percentages, were computed for categorical variables, and they were graphically presented using simple bar graphs. All analyses were conducted using SPSS version 21 (IBM Corp, Armonk, NY).

Written informed consent was obtained from all participants. This study was conducted in accordance with the principles of the Helsinki Declaration. Ethical approval for this study was granted by the Clinical Research Ethics Committee of the Faculty of Medicine, King Saud University, Riyadh, Saudi Arabia, and permission to conduct the study was granted by the hospitals administrations.

\section{Results}

Eleven public hospitals in Riyadh were invited to participate in the study, but one of them refused to participate (response rate $=91 \%$ ).

With regard to the foundational considerations of CBRN preparedness, all hospitals had a disaster committee, but only 2 of them had a CBRN planning committee. Further, CBRN considerations were included in the disaster plans of 7 hospitals. More than half of the hospitals did not share a collaborative relationship regarding preparedness for CBRN incidents with local response teams. A detailed disaster action plan was available in all hospitals, but it had been widely distributed and was readily available in only half of them.

With regard to planning activities and personnel in-charge, only half of the hospitals had a designated CBRN coordinator, but 7 of them had a medical director who oversaw CBRN preparedness activities.

Regarding training and awareness to promote CBRN preparedness, fewer than half of the hospitals reported that their emergency personnel were aware of the signs and symptoms of CBRN exposure. Only 4 hospitals had provided ongoing training to personnel who were responsible for responding to CBRN incidents. A majority of the hospitals reported that not all of the members of their CBRN response team members had received CBRN preparedness training.

With respect to the procedures that pertained to CBRN preparedness, only 3 hospitals had a disease surveillance plan that could be implemented after a CBRN incident. However, a majority of them had procedures that had to be followed to collect and protect evidence in the event of a criminal CBRN emergency. Eight hospitals had procedures that had to be followed to receive patients who have been exposed to CBRN agents prior to their treatment. A portable decontamination device was available in only 
half of the hospitals. A majority of them reported that they would have ready access to necessary equipment, dosage requirements for CBRN treatments, drug administering equipment, and antidotes in the event of a CBRN emergency (Fig. 1).

Regarding preparedness for biological incidents, a majority of the hospitals had policies and procedures for the management of Class A agents. However, the staff had been trained to recognize the signs and symptoms of exposure to these agents in fewer than half of the hospitals. A stockpile of common medications that will be needed during biological incidents was available in a majority of the hospitals, but a plan to access municipal or regional government stockpiles was available in only half of them. A majority of the hospitals had laboratory facilities that could be used to diagnose exposure to biological agents and protocols to identify and report the increased consumption of drugs. Similarly, an internal surveillance system that could be used to identify illnesses such as gastrointestinal, influenza-like, and febrile respiratory illnesses was available in a majority of the hospitals. Personal protective equipment (PPE) and plans to obtain additional PPE were available in all hospitals. Biosafety level (BSL) 2 laboratories were present in 8 hospitals, and BSL 3 laboratories were present in 6 hospitals (Table 1).

Table 1. Distribution of responses to the items of a checklist on preparedness for biological incidents among public hospitals in Riyadh between 2018 and 2019 
There is a process to inform public health authorities about Class $A^{*}$ agents that have $\quad \begin{array}{ll}10 & 100.0\end{array}$ been identified.

There is a process to rapidly follow up on all abnormal or unusual laboratory results for collected samples.

There is a process to ensure the timely notification of infection control authorities.

$8 \quad 80.0$

$\begin{array}{llll}\text { The facility's emergency preparedness plan addresses the stockpiling of medications } & 6 & 60.0\end{array}$ that are necessary to treat victims of biological incidents.

The healthcare facility currently maintains a separate stockpile of medications that can be used to treat or protect staff in the event of a biological incident.

The facility has a plan to access $C$. botulinum antitoxin. $3 \quad 30.0$

The facility vaccinates staff/physicians against influenza annually. 990.0

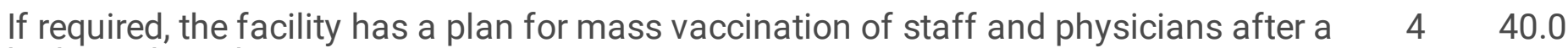
biological incident.

The emergency department identifies trends and changes in the frequency of specific $\quad \begin{array}{lll}6 & 60.0\end{array}$ discharge diagnoses.

There is a policy that specifies when the emergency department should notify any/all of the following about unusual clusters of illnesses or presentations:

Hospital infection control personnel

990.0

Other designated in-house personnel

$8 \quad 80.0$

Local public health authorities

$8 \quad 80.0$

The facility has a plan to test for biological agents $24 / 7$, if needed.

$6 \quad 60.0$

The facility's emergency preparedness plan addresses mass casualties of biological incidents.

The facility has a plan to provide pharmacy services $24 / 7$, if needed, 990.0

The facility has an ongoing respirator fit testing program for staffs that require respiratory protection.

$8 \quad 80.0$

Note: ${ }^{*}$ Class A agents include anthrax, plague, smallpox, botulism, viral hemorrhagic fevers (filoviruses like Ebola and Marburg and arena viruses like Lassa and Machupo), and tularemia.

With respect to preparedness for chemical incidents, a majority of the hospitals had access to agents like pralidoxime, tropicamide, pyridostigmine, cyanide antidote kit, dimercaprol, and acetylcysteine. However, a rapid access to stockpiles was available in only half of the hospitals. All the hospitals had an internal chemical response team, and a majority of them had access to trained responders like the hazmat team (Table 2). 
Table 2. Distribution of responses to the items of a checklist on preparedness for chemical incidents among public hospitals in Riyadh between 2018 and 2019

n $\%$

The hospital has policies and procedures that address the clinical presentation, laboratory diagnosis, infection control procedures, treatment, prophylaxis, vaccination, and public health requirements that pertain to each of the following agents:

Nerve gases (sarin, tabun, soman, VX)

$7 \quad 70.0$

Pesticides

$8 \quad 80.0$

Blood agent (cyanides)

$7 \quad 70.0$

Vesicants (sulfur mustard, Lewisite, phosgene)

$8 \quad 80.0$

Pulmonary agents (chlorine, phosgene, diphosgene, ammonia)

$8 \quad 80.0$

Riot control agents (tear gas, vomiting agents, pepper spray)

$8 \quad 80.0$

There is a provision to track antidote inventories.

$6 \quad 60.0$

The facility has equipment to monitor chemical contamination.

$8 \quad 80.0$

There is a specific policy that addresses the issue of decontamination of pregnant patients.

There are sufficient chemically resistant/vapor-tight plastic bags and containers for waste disposal.

The facility has appropriate protective clothing in accordance with results of risk assessment and regulatory requirements.

The staff has been trained in the use of this equipment.

The facility has a procedure to handle chemically contaminated deceased persons.

$4 \quad 40.0$

Regarding preparedness for radiological or nuclear incidents, a majority of the hospitals had a radiation safety officer, an internal radiation incident plan, and a plan for the evaluation and management of irradiated victims. Half of the hospitals had a radiation detection instrument. Six hospitals had a ready contact list of in-facility radiation experts. However, a contact list of external radiation experts was available in fewer than half of the hospitals. A sufficient stock of antiemetics and fluids to manage irradiated victims was available in a majority of the hospitals. However, stocks of antidiarrheal agents and potassium iodide were sufficient in fewer than half of the hospitals (Table 3).

Table 3. Distribution of responses to the items of a checklist on preparedness for radiological or nuclear incidents among public hospitals in Riyadh between 2018 and 2019 


\begin{tabular}{|c|c|c|}
\hline & $\mathrm{n}$ & $\%$ \\
\hline $\begin{array}{l}\text { The facility's disaster preparedness plan includes provisions to differentiate between } \\
\text { irradiated victims and patients who have been contaminated with a radioactive } \\
\text { material }\end{array}$ & 6 & 60.0 \\
\hline $\begin{array}{l}\text { The facility has a process to provide emergency resuscitative care to potentially } \\
\text { radiologically contaminated patients. }\end{array}$ & 7 & 70.0 \\
\hline $\begin{array}{l}\text { The hospital has an evaluation and treatment protocol that is to be used in the acute } \\
\text { care of irradiated victims }\end{array}$ & 6 & 60.0 \\
\hline $\begin{array}{l}\text { There is a specific policy that exempts pregnant staffs from } \\
\text { decontaminating/treating potentially radiologically contaminated patients. }\end{array}$ & 3 & 30.0 \\
\hline $\begin{array}{l}\text { A sufficient number of staffs know how to use instruments and interpret the resultant } \\
\text { data. }\end{array}$ & 3 & 30.0 \\
\hline There is a plan to document patients' radiation monitoring results. & 4 & 40.0 \\
\hline $\begin{array}{l}\text { There are sufficient on-site dosimeters that staffs who are responsible for } \\
\text { decontaminating and caring for patients and may have accidentally ingested or } \\
\text { inhaled radioactive materials can use. }\end{array}$ & 3 & 30.0 \\
\hline The hospital has a program to monitor dosimeters. & 4 & 40.0 \\
\hline There are sufficient plastic bags and containers for waste disposal. & 9 & 90.0 \\
\hline $\begin{array}{l}\text { There is a lead-lined or concrete area/room that can be used to store contaminated } \\
\text { clothing and waste. }\end{array}$ & 3 & 30.0 \\
\hline There is an arrangement with appropriate laboratory facilities for specimen analysis. & 5 & 50.0 \\
\hline $\begin{array}{l}\text { There is a provision for mitigation, in the event of a breach in the decontamination } \\
\text { process }\end{array}$ & 7 & 70.0 \\
\hline
\end{tabular}

\section{Discussion}

This study examined the CBRN preparedness of government hospitals in Riyadh. These findings are important because these unexpected events can wreak havoc if they are not handled appropriately. The study has also provided information about healthcare providers' competence in handling such situations. 
The availability of supplies, equipment, and logistics in a hospital is necessary but insufficient to manage disasters; adequately trained healthcare professionals play an equally important role. Hence, the present findings can be used to improve conditions that foster the CBRN preparedness of government hospitals in Riyadh. The overall response rate of the present study (91\%) was higher than what has been reported in similar studies that have been conducted in Belgium, Australia, the United States, and Mecca. $(9,10,15$, 21)

Without clearly defined objective criteria and key performance indicators of minimum requirements for staff preparedness, it is not possible to assess hospital preparedness.(22) Many measures of disaster preparedness exist $(15,24)$, one of which assess 3 associated competencies: general competencies, specific competencies of emergency nurses, and rapid response competencies of first-line healthcare providers (23). However, the CBRNE Plan Checklist was adapted and used in the present study because we found it to be most appropriate to the Saudi context.

All the participating hospitals had disaster committees and detailed disaster action plans. However, only a few of them had disaster units and CBRN planning committees. Similarly, very few hospitals had conducted combined drills in collaboration with local agencies. This finding underscores their lack of initiative in mitigating the effects of disasters and the need to delineate the finer details of plans that pertain to combined drills and specific disaster units and strengthen CBRN planning by constituting CBRN planning committees. This finding is similar to Shalhoub et al's findings that all their participating private hospitals in Riyadh had a hospital disaster plan and committee but were inadequately prepared for emergency drills. (16)

In this study, the disaster plans of 7 hospitals included CBRN considerations. This figure is higher than what was reported in a Belgian study (53\%). (10) Combined drills were conducted in collaboration with local agencies in very few hospitals, and this finding concurs with those of Wetter et al and Al-Shareef et al. $(15,21)$

In the present study, only half of the hospitals had a designated CBRN coordinator. A CBRN coordinator oversees CBRN preparedness activities. Therefore, their presence can facilitate the planning and execution of preparedness activities. In a majority of the participating hospitals, the medical director oversaw CBRN preparedness activities. Further, hospital personnel had received inadequate CBRN preparedness training. Hospital personnel's knowledge about the signs and symptoms of CBRN exposure was poor. Frontline healthcare workers play a crucial role in treating victims of disasters within a hospital. Poor training and a lack of knowledge can adversely affect the effectiveness of CBRN preparedness. Healthcare workers in Australia, the United States, and Mecca receive advanced training in disaster management. $(9,15,21)$ The hospitals were found to have satisfactorily assigned roles and responsibilities that pertain to the management of CBRN events to different personnel. Responsibilities that pertain to issues such as triage, security, chain of custody, storage of contaminated items, and transportation of contaminated items and deceased persons had been assigned in a majority of the study hospitals. This is an important component of CBRN preparedness because it is difficult to assign 
such responsibilities during disasters. However, the responsibility of procuring equipment had not been assigned in a majority of the hospitals.

Mass communication systems disseminate important messages to all staff members and the general population during disasters. Therefore, it is an important component of disaster management. However, this system was present in fewer than half of the participating hospitals. Decontamination devices help prevent the spread of hazardous CBRN materials from contaminated bodies or objects to other individuals, equipment, and facilities. Encouragingly, facilities to isolate contaminated victims were available in $80 \%$ of the hospitals. However, decontamination devices were available in only half of them, and contaminated items could be contained in only $40 \%$ of them. Thus, there is an urgent need to improve the availability of decontamination devices in hospitals because they can prevent mass contamination and mitigate the health impact of incidents that involve contaminants. The availability of decontamination facilities in the participating hospitals of the present study was poorer than what has been reported for some western countries $(21,25)$ but better than what has been reported for Australia and Mecca. Similarly, systems that can contain contaminated fluid were found to be available in only $40 \%$ of the government facilities in Mecca. (15)

With regard to preparedness for biological incidents, most hospitals had policies and procedures to diagnose and manage Class A agents. However, only half of them had trained their staff in these policies and procedures. Similarly, fewer than half of the hospitals had trained their staff to recognize the signs and symptoms of exposure to Class A agents. The mere availability of policies and procedures is insufficient to manage the aftermath of disasters. Hence, there is a greater need to focus on the education and training of healthcare workers to improve hospital preparedness. Medications are an important component of emergency and disaster management. It is necessary to stockpile them so that they can be used whenever there is a high demand. Nevertheless, only 6 hospitals had plans to stockpile medications. Further, only 3 hospitals had a separate stockpile for staff. Half of the hospitals did not plan to procure medicines from municipal or regional stockpiles during an emergency. All these factors can seriously affect the availability of drugs during disasters and compromise the quality of services that need to be provided. The availability of antibiotics was satisfactory across hospitals, but the antitoxin for C. botulinum was available in fewer than half of the hospitals. Such organisms can be used in bioterrorist attacks. These findings are similar to those of a study that was conducted in Mecca. (15) Similarly, only $56 \%$ of the hospitals in the Unites States were found to have adequate supplies to handle chemical or biological attacks. (25)

Nine hospitals had conducted an annual vaccination program against influenza for their staff. Most hospitals had policies to identify unusual surges in the rates of particular types of illnesses and facilities to diagnose illnesses that are caused by organisms that can be used in bioterrorist attacks (anthrax, brucellosis, plague). Similarly, most hospitals had emergency preparedness plans to manage mass casualties of biological agents. All hospitals had adequate on-site PPE. The availability of vaccination programs in hospitals was similar to what was reported in a Belgian study, (10) and the availability of 
PPE was similar to what has been reported in studies that have been conducted in countries other than Saudi Arabia. $(9,10)$

Most hospitals had policies and procedures to treat individuals who have been affected by nerve gases, pesticides, vesicants, pulmonary agents, and other substances. Similarly, in a majority of the hospitals, antidotes like atropine, diazepam, pralidoxime, and tropicamide were available. A study that was conducted among private hospitals in Riyadh also found that a stockpile of antidotes for organophosphate and cyanide poisoning was available in most hospitals. (16) However, almost half of the hospitals did not have rapid access to stockpiles of drugs and facilities to track antidote inventories. This merits attention because victims of disasters require urgent care, and delays in procuring medicines and equipment can delay effective responses. Keim et al found that hospitals in a major city in the United States were insufficiently prepared to address emergencies that involve nerve agents and cyanide poisoning.(26) Similar to the present findings, the availability of adequate amounts of antidotes like atropine, pralidoxime, and diazepam in hospitals have also been reported by studies that have been conducted in the United States and Belgium. $(10,27)$ However, Eliseo et al found that these compounds were unavailable in hospitals.(9) In the present study, a majority of the hospitals had facilities to monitor chemical contamination and bags and containers to discard chemical waste. Protective clothing was also available in more than half of the hospitals, but 6 hospitals had not trained their staff to use such equipment. The present findings about the availability of facilities to manage contaminated water are similar to those of a British study. (28)

A majority of the participating hospitals had a radiation safety officer and plans to manage internal radiation incidents and irradiated victims. More than half of the hospitals did not have dosimeters that staff could use. This is an important finding because radiation detection instruments can be used to estimate the risk of a nuclear incident. Further, they are essential to the safety of staff members. The inadequate availability of radiation detection measures in hospitals was also reported in another Belgian study. (10) In a study that was conducted in the United States, the availability of equipment, protection, and treatment that pertain to radiation trauma was found to be inadequate. (29) In the present study, most hospitals had a contact list of in-facility radiation experts, but only a very few of them had access to external experts. In a study that was conducted in Australia, most hospitals were found to have access to specialist advice in the event of a CBRN incident; these findings are similar to the present results. (9) This finding is significant because external experts serve as important sources of information during an emergency. Although most of the participating hospitals had adequate facilities, equipment, and logistics to handle radiation-related incidents, they varied in the extent to which these resources were available.

\section{Strengths and limitations of the study}

The present study has several strengths. First, the current study was one of the first to examine the CBRN preparedness of public hospitals in Riyadh. The present findings are likely to serve as an indispensable source of empirical evidence in future disaster planning and management in public hospitals. Second, the use of the CBRNE Plan Checklist ensured that a comprehensive and valid set of information about the

Page $11 / 17$ 
CBRN preparedness of hospitals were collected and examined. Third, all the hospital heads were interviewed by a single researcher. This enhanced the reliability of the findings and eliminated the possibility of inter-observer variations. Fourth, the high response rate $(>90 \%)$ that emerged in the present study permits the results to be generalized to other similar cities within the Kingdom of Saudi Arabia. Finally, the hospital heads who were in charge of disaster preparedness are likely to have been made aware of several lacunae in their facilities over the course of the interview, and this may have stimulated them to conduct an internal assessment and improve their preparedness.

A few limitations of the present study must be borne in mind when its findings are interpreted. The incident commanders or heads of emergency departments of the participating hospitals provided all the data. Thus, respondents' reluctance to disclose the inadequacies of their hospitals may have biased the data that were collected. Indeed, respondents' reports about the availability of inventories, equipment, and logistics were not crosschecked through first-hand observations. Similarly, the knowledge and skills of healthcare workers were not directly assessed; instead, they were indirectly assessed based on the reports of persons in-charge. This may have resulted in the under- or overestimation of their abilities.

\section{Conclusions}

The CBRN preparedness of government hospitals in Riyadh was found to be less than satisfactory. Many encouraging findings, such as the following, also emerged: availability of a disaster committee, triage personnel, and plans to manage internal and external disasters, inclusion of considerations that are related to CBRN events in disaster plans, ability to provide medical care in response to CBRN incidents, collaboration with police to manage decontamination sites, availability of drug administration equipment, collaboration with public health authorities, implementation of staff vaccination programs, laboratory facilities to test for biological agents, and availability of antibiotics, PPE, and major drugs that are needed to treat victims of chemical and radiological events. However, we also found that there was considerable scope for improvement in several other areas such as the training of healthcare workers, assignment of appropriate personnel to roles that are required during emergencies, stockpiling of appropriate medications, implementation of drills, and management of contaminated deceased persons.

\section{Recommendations And Future Directions}

All hospitals that currently do not have a CBRN coordinator should immediately appoint or designate an experienced official as a CBRN coordinator and establish disaster management units. All hospitals should prepare plans to regularly conduct drills in collaboration with local emergency response units. All staffs that are designated to handle equipment that are related to CBRN events should be sufficiently trained to identify and use them. Hospital management should take immediate steps to identify personnel who can occupy vacant positions that are related to CBRN planning. Further, the roles and responsibilities of these personnel should be clearly defined, and they must be provided with appropriate training. Hospital management should identify mechanisms and pathways to access local, regional, and national stockpiles and appoint an official who can organize these activities. All hospitals should develop 
clear plans and standard operating procedures to handle deceased persons who may have been contaminated with CBRN materials. Guidelines, protocols, and training manuals should be developed by the Ministry of Health and widely distributed to all hospitals so that they are better equipped to respond to CBRN emergencies. Similar studies on CBRN preparedness should be conducted among hospitals in other cities within the Kingdom of Saudi Arabia, in a temporal order that corresponds to their relative risk of experiencing CBRN events.

\section{Declarations}

\section{Ethical Approval}

This study complied with the ethical standards, and with laws and regulations and any applicable guidelines of the Kingdom of Saudi Arabia where the study was conducted.

\section{Consent to participate:}

Not applicable

\section{Consent for publication:}

Not applicable

\section{Availability of supporting data:}

Not applicable

\section{Competing interests:}

No competing of interest

\section{Funding:}

No funding

\section{Author contributions:}

$A A$ and $A K$ conceived the study. AA prepared the questionnaire and collected data. AK provided critical inputs that shaped the study design and development of the checklist. AA conducted data analysis and wrote the first draft of the manuscript with critical inputs from AK. All authors have reviewed and approved the final manuscript.

\section{Acknowledgments:}

The authors thank the study participants for their valuable time and patience. 


\section{References}

1. Lorin HG, Kulling PE. The Bhopal tragedy--what has Swedish disaster medicine planning learned from it? J Emerg Med. 1986;4(4):311-6.

2. World Nuclear Association. Chernobyl Accident 1986. Available from: http://www.worldnuclear.org/information-library/safety-and-security/safety-of-plants/chernobyl-accident.aspx [Accessed 09 May 2018].

3. Harris R, Paxman J. A Higher Form of Killing: The Secret History of Chemical and Biological Warfare. New York: Random House Trade Paperbacks; 2002. 336 p. Available from: https://archive.org/details/B-001-000-001 [Accessed 09 May 2018]

4. Sharma RK. Chemical, Biological, Radiological, and Nuclear disasters: Pitfalls and perils. J Pharm Bioallied Sci. 2010;2(3):155-6.

5. Keim M, Kaufmann AF. Principles for emergency response to bioterrorism. Ann Emerg Med. 1999;34(2):177-82.

6. Abd elazeem H, Adam S, Mohamed G. Awareness of Hospital Internal Disaster Management Plan among Health Team Members in A University Hospital. Life Science Journal. 2011;8(2):42-52.3.

7. Treat KN, Williams JM, Furbee PM, Manley WG, Russell FK, Stamper CD. Hospital preparedness for weapons of mass destruction incidents: an initial assessment. Ann Emerg Med. 2001;38(5):562-5.

8. Hsu EB, Casani JA, Romanosky A, Millin MG, Singleton CM, Donohue J, et al. Critical assessment of statewide hospital pharmaceutical surge capabilities for chemical, biological, radiological, nuclear, and explosive incidents. Prehospital Disaster Med. 2007;22(3):214-8.

9. Eliseo T, Lee CC, Aitken P, Caldicott DG, Edwards NA, others. Terror Australis 2004: preparedness of Australian hospitals for disasters and incidents involving chemical, biological and radiological agents. CritCareResusc. 2008;10(2):125.

10. Mortelmans LJM, Van Boxstael S, De Cauwer HG, Sabbe MB, Belgian Society of Emergency and Disaster Medicine (BeSEDiM) study. Preparedness of Belgian civil hospitals for chemical, biological, radiation, and nuclear incidents: are we there yet? Eur J Emerg Med. 2014;21(4):296-300.

11. Hakeem O, Jabri S. Adverse birth outcomes in women exposed to Syrian chemical attack. Lancet Glob Health. 2015;3(4):e196.

12. Eisenkraft $A$, Gilburd $D$, Kassirer $M$, Kreiss $Y$. What can we learn on medical preparedness from the use of chemical agents against civilians in Syria? Am J Emerg Med. 2014;32(2):186.

13. Alshehri SA, Rezgui Y, Li H. Public perceptions and attitudes to biological risks: Saudi Arabia and regional perspectives. Disasters. 2016;40(4):799-815.

14. Alzahrani F, Kyratsis Y. Emergency nurse disaster preparedness during mass gatherings: a crosssectional survey of emergency nurses' perceptions in hospitals in Mecca, Saudi Arabia. BMJ Open. 2017;7(4):e013563.

15. Al-Shareef AS, Alsulimani LK, Bojan HM, Masri TM, Grimes JO, Molloy MS, et al. Evaluation of Hospitals' Disaster Preparedness Plans in the Holy City of Makkah (Mecca): A Cross-Sectional 
Observation Study. Prehospital Disaster Med. 2017;32(1):33-45.

16. Bin Shalhoub AA, Khan AA, Alaska YA. Evaluation of disaster preparedness for mass casualty incidents in private hospitals in Central Saudi Arabia. Saudi Med J. 2017;38(3):302-6.

17. Reuters. Barrage of missiles on Saudi Arabia ramps up Yemen war. Reuters. 2018 Mar 26; Available from: https://www.reuters.com/article/us-yemen-security-missiles/barrage-of-missiles-on-saudiarabia-ramps-up-yemen-war-idUSKBN1H21HQ [Accessed 9 May 2018]

18. World Nuclear Association. Nuclear Power in Saudi Arabia. Available from: http://www.worldnuclear.org/information-library/country-profiles/countries-o-s/saudi-arabia.aspx [Accessed 23 April 2018].

19. Al-Haddad M, Siddiqi GH, Al-Zaid R, Arafah A, Necioglu A, Turkelli N. A Basis for Evaluation of Seismic Hazard and Design Criteria for Saudi Arabia. Earthq Spectra. 1994;10(2):231-58.

20. Centre for Excellence in Emergency Preparedness. CBRNE plan checklist. Ontario, Canada: CEEP, 2009. Available at http://www.ceep.ca/publications/tools/cbrneplanchecklist.pdf [Accessed 9 May 2018]

21. Wetter DC, Daniell WE, Treser CD. Hospital preparedness for victims of chemical or biological terrorism. Am J Public Health. 2001;91(5):710-6.

22. Alexander D. Towards the development of a standard in emergency planning. Disaster Prev Manag Int J. 2005;14(2):158-75.

23. Mitchell CJ, Kernohan WG, Higginson R. Are emergency care nurses prepared for chemical, biological, radiological, nuclear or explosive incidents? Int Emerg Nurs. 2012;20(3):151-61.

24. Agency for Healthcare Research and Quality. Preparedness for Chemical, Biological, Radiological, Nuclear, and Explosive Events: Questionnaire for Health Care Facilities. Rockville, Maryland: U. S. Department of Health and Human Services, 2007. Available at https://archive.ahrq.gov/prep/cbrne/cbrneqrespondent.pdf [Accessed 9 May 2018]

25. Bennett RL. Chemical or biological terrorist attacks: an analysis of the preparedness of hospitals for managing victims affected by chemical or biological weapons of mass destruction. Int J Environ Res Public Health. 2006;3(1):67-75.

26. Keim ME, Pesik N, Twum-Danso NAY. Lack of hospital preparedness for chemical terrorism in a major US city: 1996-2000. Prehospital Disaster Med. 2003;18(3):193-9.

27. Greenberg MI, Jurgens SM, Gracely EJ. Emergency department preparedness for the evaluation and treatment of victims of biological or chemical terrorist attack. J Emerg Med. 2002;22(3):273-8.

28. Williams J, Walter D, Challen K. Preparedness of emergency departments in northwest England for managing chemical incidents: a structured interview survey. BMC Emerg Med. 2007;7:20.

29. Jasper E, Miller M, Sweeney B, Berg D, Feuer E, Reganato D. Preparedness of hospitals to respond to a radiological terrorism event as assessed by a full-scale exercise. J Public Health Manag Pract. 2005;Suppl:S11-16. 
Figures

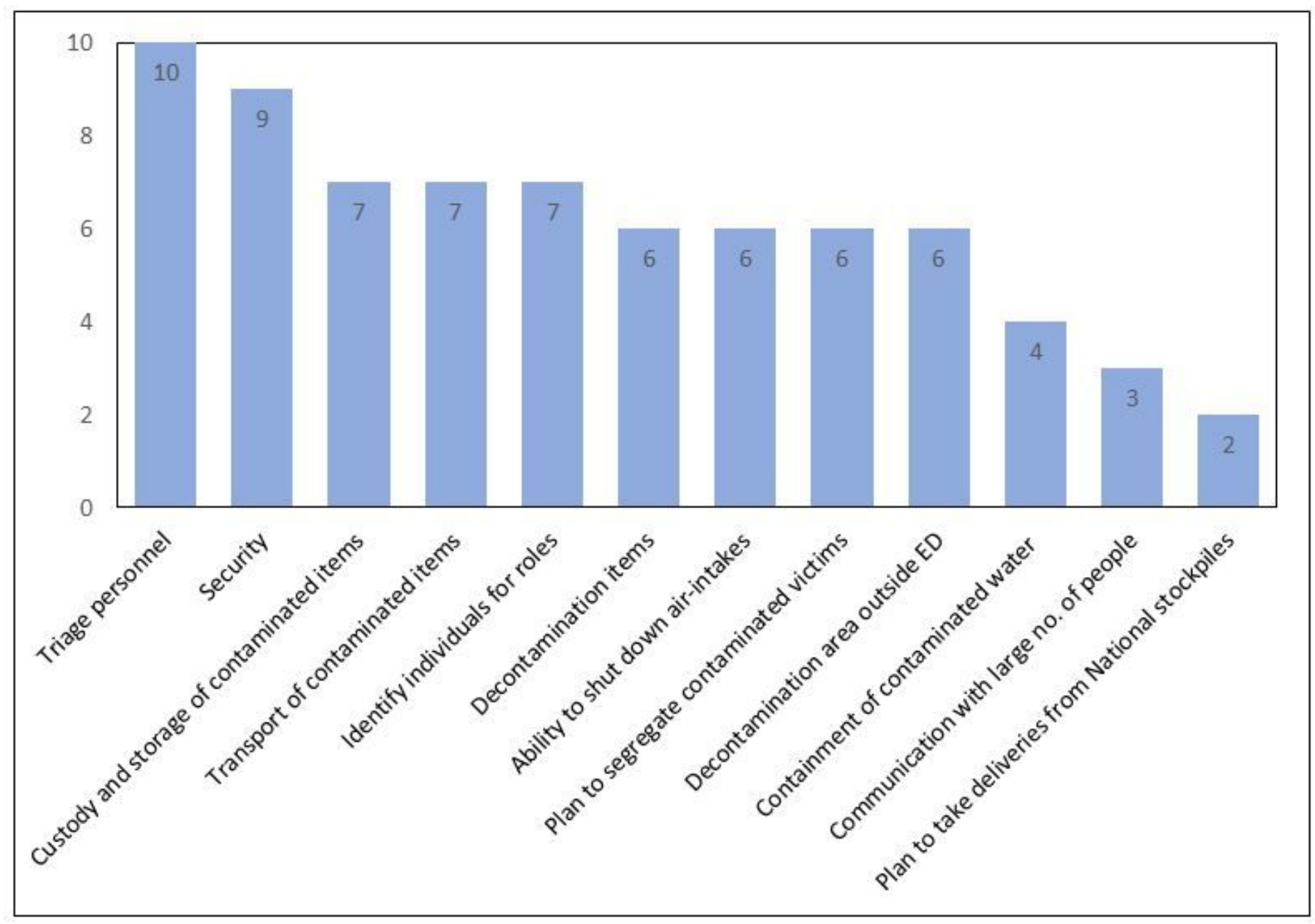

Figure 1

Availability of inventories, equipment, and logistics for chemical, biological, radiological, and nuclear preparedness in public hospitals in Riyadh between 2018 and 2019 


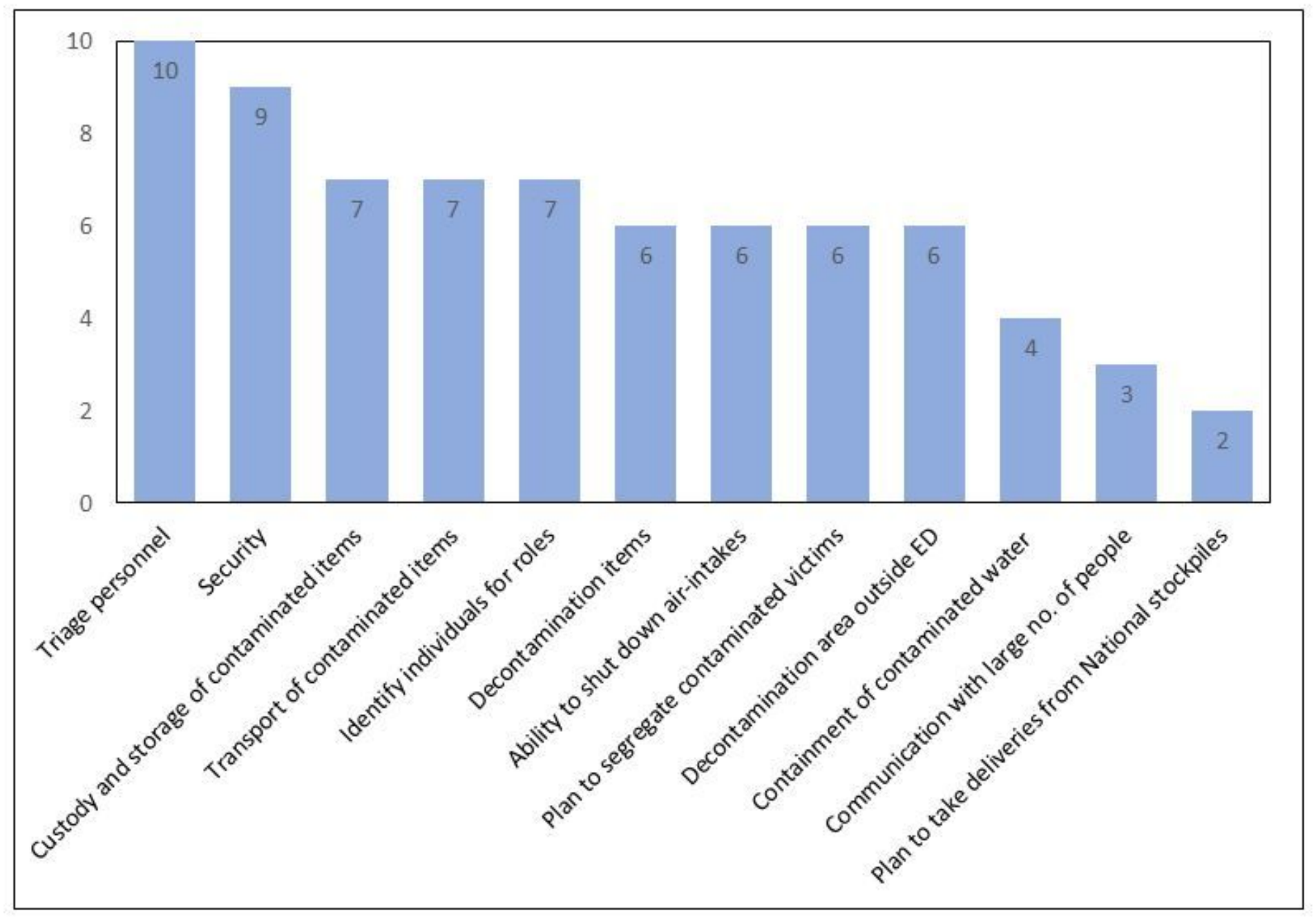

Figure 1

Availability of inventories, equipment, and logistics for chemical, biological, radiological, and nuclear preparedness in public hospitals in Riyadh between 2018 and 2019 